Boletín de la Sociedad Botánica de México 52: 105-113, 1992

DOI: $10.17129 /$ botsci.1407

Bol. Soc. Bot. México 52:105-113 (1992)

\title{
Schaffneria nigripes (Aspleniaceae): morfogénesis del gametofito y anatomía y morfología del esporofito
}

\author{
Ramón Riba, Blanca PéreZ-García y Martha PÉrez-García ${ }^{1}$
}

\begin{abstract}
RESUMEN. Se aportan datos de la morfología y la anatomía del esporofito y del desarrollo del talo gametofito de Schaffneria nigripes Fée (Aspleniaceae); las hojas son enteras y romboides a obovadas, con estomas solamente en la cara abaxial; el mesófilo es un parénquima esponjoso sin parénquima compacto; la estela, con una enđodermis bien definida, es una sifonostela ectofloica. Las esporas tienen viabilidad larga y su germinación es del tipo Vittaria; los gametofitos maduros son cordiformes irregulares, con pelos no glandulares en ambas superficies y en los márgenes.
\end{abstract}

ABSTRACT. Data about the morphology and anatomy of the sporophyte and the gametophyte devełopment of Schaffncria nigripes Fée (Aspleniaceae) are given in this paper; the leaves are entire, rhomboid to obovate, with stomata in the abaxial side of the lamina; the mesophyll is a spongy parenchyma; the stele, with a well defined endodermis, is an ectophloic siphonostele. The spores have long viability and the germination is Vittaria type; the mature gametophytes are irregularly cordate, with non-glandular hairs in both surfaces and in the margins.

Schaffneria nigripes Fée (Aspleniaceae) (fig. 1) es un helecho poco conocido a pesar de que ha sido recolectado en México en los estados de Tamaulipas, San Luis Potosí, Veracruz, Oaxaca y Chiapas; también se encuentra en Guatemala, Costa Rica (Gómez P., 1973) y Cuba (Tryon y Tryon, 1982); esta aparente disyunción en América Central se debe, en nuestra opinión, a que es muy escaso y de pequeño tamaño, por lo que fácilmente pasa inadvertido entre las otras plantas del sotobosque; en los herbarios consultados (ENCB, GH, MEXU, MO y UAMIZ) no hay ejemplares de El Salvador, Honduras, Nicaragua y Costa Rica. Por los datos de las etiquetas de herbario de los

${ }^{1}$ Departamento de Biología, División de C.B.S., Universidad Autónoma Metropolitana-Iztapalapa. Apdo. Postal 55-535, CP, 09340, México, D.F.

Riba R, Pérez-García B, Pérez-García M. 1992. Schaffneria nigripes (Aspleniaceae): morfogénesis del gametofito y anatomía y morfológía del esporofito. Boletín de la Sociedad Botánica de México 52: 105-113. 


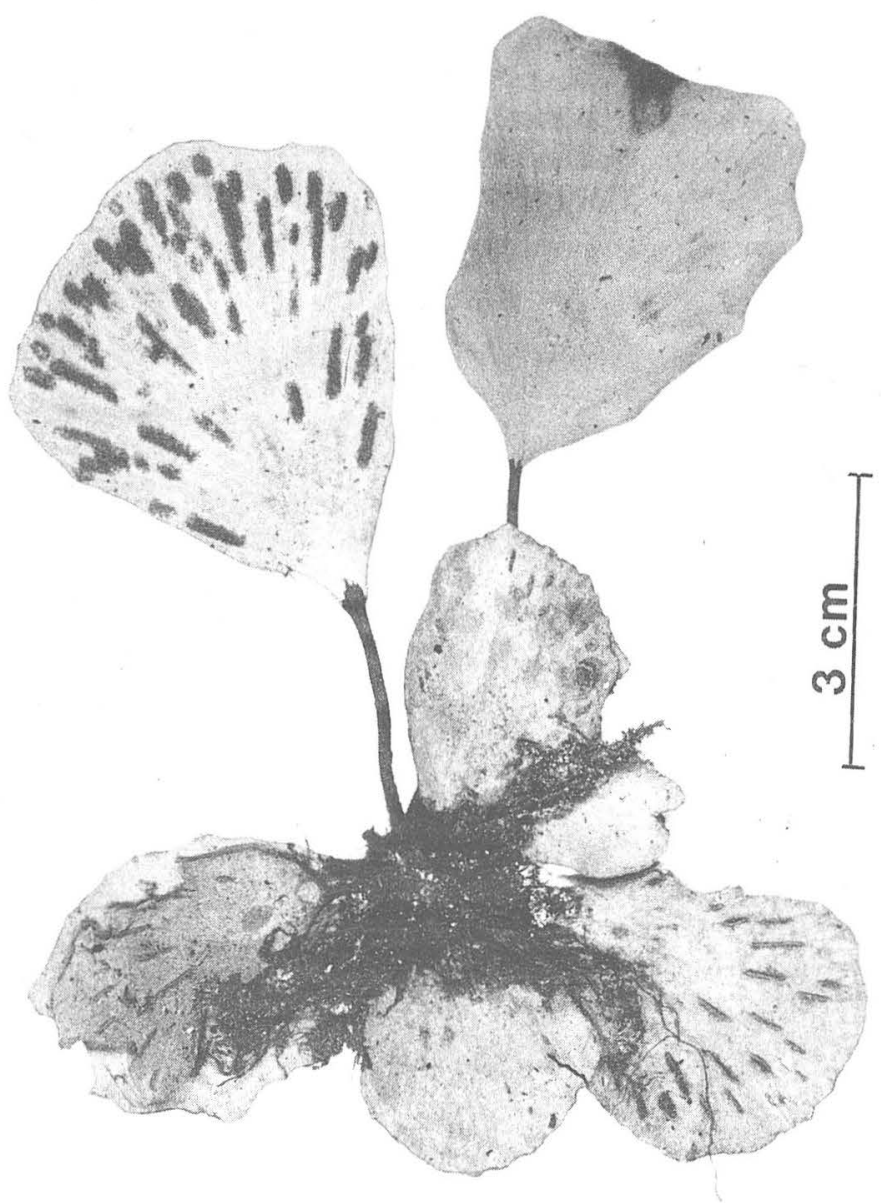

Fig. 1. Schaffneria nigripes Fée (Riba 1313, UAMIZ).

ejemplares examinados y por observación en el campo en México, se infiere que crece en sitios sombreados y con afloramientos de rocas calizas en bosques mesófilos, entre 800-1500 metros de altitud.

En esta publicación se ofrecen datos de la morfología y la anatomía del esporofito así como del desarrollo del talo gametofito hasta su madurez. 


\section{Descripción}

Planta rupícola, de $10-13 \mathrm{~cm}$, rizoma erecto, corto; hojas de $9-13 \mathrm{~cm}$, enteras; pecíolo de $3-6 \mathrm{~cm}$, de color oscuro casi negro, con escasas escamas clatradas en su base y escasos tricomas cuando joven; lámina de $4-7 \mathrm{~cm}$, romboide a anchamente obovada, algo carnosa; venación reticulada formando aréolas alargadas sin venillas incluidas y con venillas cortas libres que no llegan al borde de la lámina; soros alargados, sobre las venas en la mitad distal de la lámina; indusio asplenioide, blanquecino y translúcido, desplazado lateralmente por los esporangios cuando éstos maduran; esporas de color pardo oscuro, casi negras, monoietes, con pliegues y áreas adyacentes reticulado-equinados, 64 por esporangio.

\section{MATERIALES Y MÉTODOS}

Las esporas se obtuvieron de: a) material de herbario de Oaxaca (Mickel 7333, recolectado en 1973, ENCB) y de Veracruz (Riba 1313, recolectado en 1983, UAMIZ) y b) material fresco de Cuba (Jardín Botánico Nacional, Núm. de registro de introducción de plantas vivas 1987-3704, Habana, Cuba).

Las esporas se obtuvieron raspando ligeramente los soros de las hojas fértiles con una aguja de disección, sobre una hoja de papel para recoger el material desprendido (esporas y restos de indusio y esporangios).

Las esporas recolectadas de esta manera se sembraron en cajas de Petri $(5 \times 1 \mathrm{~cm})$ con agar y medio de Thompson (Klekowski, 1969 y Pérez-García, 1988); de cada muestra se sembraron 6 cajas y una de ellas se forró con papel estaño doble para determinar la capacidad de germinación de las esporas en la oscuridad. Las cajas se expusieron a luz blanca fría ( $70 \mathrm{~W}$ a $45 \mathrm{~cm}$ de distancia), con termoperíodo de $18-25^{\circ} \mathrm{C}$ y fotoperíodo de 12 hrs de oscuridad.

Las observaciones subsecuentes se hicieron cada tres días para determinar el período de latencia y la viabilidad excepto la caja forrada con papel estaño, la que se descubrió hasta después de treinta días; los dibujos se hicieron con una cámara clara American Optical para microscopio compuesto American Optical y las fotomicrografías se obtuvieron con un fotomicroscopio Carl Zeiss.

El material de los esporofitos estudiado anatómicamente resultó de la siembra de las esporas de Mickel 7333 y Riba 1313. Para los cortes se usó la técnica de inclusión de parafina, cortes de $15-20 \mu \mathrm{m}$ de grosor y las técnicas de tinción usadas fueron las de safranina-verde rápido (Sass, 1958) y azul de toluidina al $0.25 \%$ en solución acuosa. Para la observación de los estomas, las hojas fueron aclaradas en solución acuosa de hidróxido de sodio al $5 \%$ por varios días con una aclaración final en una solución acuosa de hipoclorito de sodio comercial al 20\% (Thurston, 1969); las fotomicrografías se obtuvieron con un fotomicroscopio Carl Zeiss. Las medidas de las características foliares fueron tomadas en un campo de 400x, para los estomas el campo fue de $256 x$. 


\section{Observaciones}

Gametofito. Las esporas de Schaffneria nigripes Fée son monoletes con perina y miden de 25-35 x 35-55 $\mu \mathrm{m}$ (fig. 2). La germinación se inició en un período de 10-13 días excepto en las cajas mantenidas en la oscuridad, en las que no hubo germinación, y se inició con la formación de la primera célula rizoidal y la célula protálica (fig. 3) correspondiendo al tipo Vittaria (Nayar y Kaur, 1971).

La formación de la lámina protálica se inicia cuando el filamento germinativo tiene 6 células de largo (fig. 4), y las células terminales del filamento toman parte en su desarrollo a los 15 días. La célula meristemática obcónica se forma de una de las células hijas siguientes a la célula terminal porque en ésia se diferencia un pelo antes de iniciarse el desarrollo de la lámina protálica, por lo que sus divisiones se detienen.

A los 20 días, se tiene una lámina protálica con la célula meristemática de origen lateral (fig. 5) y después se transforma en un meristemo central, por lo que su desarrollo corresponde al tipo Aspidium. La lámina protálica joven es largamente espatulada, de forma un tanto asimétrica y con pelos en la punta de lóbulos marginales de la lámina (fig. 8).

En esta especie el desarrollo de los pelos es precoz, presentándose desde las fases filamentosas hasta la fase adulta (figs. 4-8); son unicelulares, delgados, alargados, con cloroplastos y no observamos desarrollo de ninguna secreción extracelular; su posición puede ser marginal y en ambas superficies del gametofito (fig. 9) y aparecen desde los 15 días de edad. Cuando el gametofito tiene de 20-36 días la lámina protálica es bidimensional, con la célula meristemática obcónica lateral y sin desarrollo de gametangios; éstos se inician a partir de los 86 días.

Los anteridios se encuentran esparcidos en el cojinete o a ambos lados del mismo; tienen una célula basal, una anular y una opercular. Los arquegonios se diferencian en la parte anterior del cojinete y son del tipo común de los helechos leptosporangiados, con cuellos cortos y orientados hacia el meristemo apical del gametofito.

A los 190 días los gametofitos son cordiformes, con un cojinete delgado, con el borde irregularmente ondulado y con lobos terminados en un pelo; a esta edad el gametofito laminar tiene abundantes pelos en ambas superficies y numerosos rizoides hialinos. Aproximadamente entre los 200 a 210 días se hace evidente la primera hoja del esporofito, que es entera, cortamente espatulada y circinada. A pesar de que los ejemplares Mickel 7333 y Riba 1313 tenían 11 y 4 años respectivamente de haber sido recolectados y de haber sido expuestos a los procedimientos usuales de desecación, no hubo diferencias apreciables en cuanto a viabilidad y tasa de germinación de sus esporas con respecto a las esporas frescas del material cubano; el material mexicano tuvo un porcentaje de germinación de $85 \%$ y el procedente de Cuba lo tuvo en $90 \%$.

Anatomia (descripciones hechas con base en plantas de 24 meses de edad).

Lámina foliar. El grosor promedio de la lámina joven es de $240 \mu \mathrm{m}$ y el de la lámina adulta es de 500-700 $\mu \mathrm{m}$; la epidermis del haz está formada por células con una delgada cutícula y de contorno sinuoso (fig. 10), las que se van haciendo más pequeñas hacia los bordes de la hoja. El grosor medio de la epidermis del haz (incluyendo la cutícula) es 




Figs. 2-9. Esporas y fases tempranas de desarrollo del gametofito de Schaffneria nigripes Fèe, fig. 2. Espora, fig. 3. Inicio de la germinación, 12 días después de la siembra, fig. 4. Gametofito filamentoso, 15 días, fig. 5. Gametofito laminar con célula meristemática lateral y pclos marginales, 20 días, figs. 6-7. Gametofitos bidimensionales, 36 días, figs. 8-9. Detalle de los pelos marginales y superficiales. 
de $21 \mu \mathrm{m}$ y el del envés es de $29.5 \mu \mathrm{m}$. Los estomas se encuentran solamente en el envés de la hoja con una densidad de 16 estomas por $\mathrm{mm}^{2}$ y las células oclusivas tienen una longitud promedio de $42.5 \mu \mathrm{m}$; las células que rodean a los estomas son similares a las demás de la epidermis (fig. 11), por lo que éstos son anomocíticos y sobresalen ligeramente de la superficie, observándose incluso un ligero traslape del borde externo de las células oclusivas sobre las células epidérmicas subyacentes (fig. 12). El mesófilo está formado únicamente por parénquima esponjoso, con células clorofílicas de forma irregular y varios brazos cilíndricos y los que están dirigidos hacia el haz y el envés se ponen en contacto con cortas prolongaciones de paredes muy engrosadas de las células epidérmicas (fig. 13). Las venas están representadas por haces bicolaterales rodeados por la vaina del haz vascular, en este caso, formada de células parenquimáticas sin espacios entre ellas.

Pecíolo. En sección transversal es triangular redondeado o terete con la cara adaxial aplanada. La epidermis es monoestratificada, con un grosor promedio de $23.5 \mu \mathrm{m}$, la cara externa está esclerosada (fig. 15) dejando sólo una pequeña luz en cada célula hacia el interior. Por debajo de la epidermis hay un parénquima incoloro cuyas células son isodiamétricas, grandes, con citoplasma denso y escasos espacios intercelulares pequeños, que se hacen algo más pequeños hacia el exterior. El único haz vascular del pecíolo está delimitado al exterior por una endodermis bien definida y un estrato de periciclo y es del tipo colateral (fig. 16).

Rizoma. En corte transversal (fig. 17) se observa de afuera hacia adentro, una epidermis esclerosada probablemente pluriestratificada, la corteza está formada por células parenquimáticas, isodiamétricas, de contenido celular denso sobre todo las que están hacia la parte más externa y en algunas se ven núcleos redondeados bien definidos; en el límite interno de la corteza se observa la endodermis con las caracterìsticas bandas de Caspari y por dentro de ella 2-3 estratos de células del periciclo; la estela es una sifonostela ectofloica (fig. 18).

Raíz. Del rizoma parten raíces que en corte longitudinal presentan una epidermis pluriestratificada de paredes algo engrosadas, con gran cantidad de taninos; la corteza, la endodermis y el periciclo no se observaron, el único haz vascular (fig. 14) tiene metaxilema escalariforme, rodeado por elementos del floema con núcleos grandes y bien definidos.

\section{DISCUSIÓN}

Germinación. Las esporas de Schaffneria nigripes no parecen sufrir menoscabo de su capacidad germinativa por los procedimientos usuales de desecación por calor de los ejemplares de herbario, pues no hubo diferencias apreciables en el período de latencia y en la viabilidad de las esporas de las tres fuentes mencionadas.

Gametofito. La ubicación de S. nigripes en Aspleniaceae y su relación obvia con Asplenilum (Smith, 1981), aparente por características del esporofito, se ve reforzada por algunos rasgos del gametofito. En S. nigripes la célula terminal del filamento inicial desarrolla un pelo grueso, por lo que la célula meristemática se forma lateralmente una 

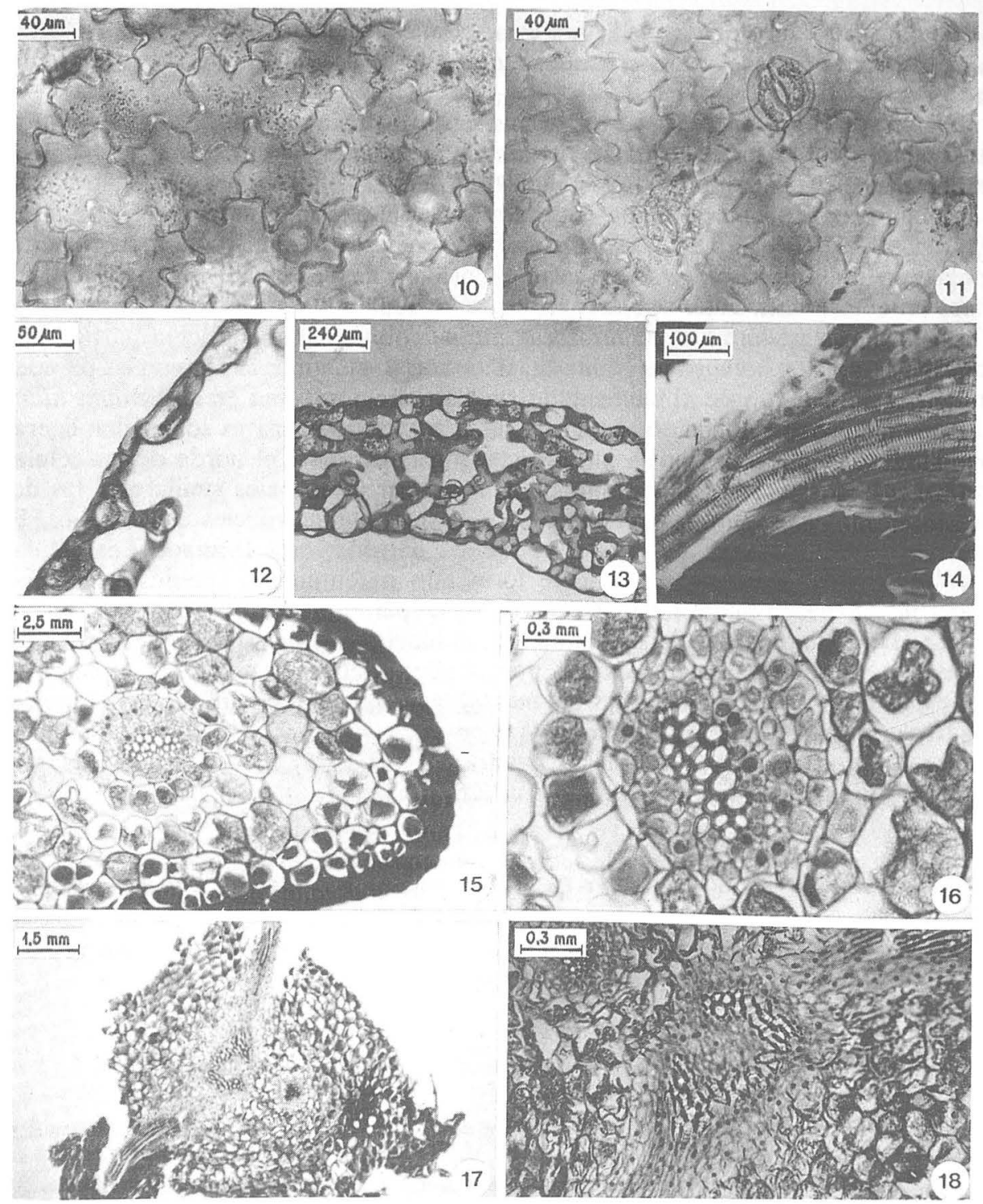

Figs. 10-18, fig. 10. Epidermis del haz, fig. 11. Epidermis del envès, fig. 12. Estoma en vista transversal, fig. 13. Corte transversal de hoja mostrando el parénquima esponjoso, fig. 14. Haz vascular de la raíz en vista longitudinal, fig. 15. Pecíolo, corte transversal, fig. 16. Haz vascular ùnico del pecíolo, fig. 17. Rizoma, corte transversal, fig. 18. Sifonostela ectofloica mostrando tres trazas foliares y una laguna foliar. 
o dos células por debajo de aquella; por esta razón el gametofito laminar es asimétrico. Este carácter lo comparte con Asplenium pellucidum, A. praemorsum y $A$. septentrionale entre otras especies (Nayar, et al., 1968).

El gametofito desarrollado es piloso marginalmente y en ambas superficies, de manera similar a los gametofitos de algunas especies asiáticas de Asplenium, como $A$. aethiopicum y $A$. crinicaule (Nayar, et al., 1968).

Esporofito. En el pecíolo aparentemente no hay tejido mecánico en el sentido de Ogura (1972) y la rigidez del pecíolo con el consecuente sostén de la hoja se obtienen por la epidermis engrosada; el único haz oval del pecíolo inicia una división en dos o tres haces inmediatamente antes de entrar en la lámina, dependiendo de la edad de la planta.

Las células epidérmicas de la lámina no tienen ninguna disposición particular y podrían ser del tipo homogéneo (Poirault, 1893 citado en Ogura, 1972), con las paredes onduladas en el haz y en el envés vistas superficialmente como en Asplenium nidus (Ogura, 1972). Los estomas son superficiales y las células oclusivas sobresalen ligeramente en sus bordes externos y pueden cubrir parcialmente el borde de las células epidérmicas contiguas. La epidermis tiene en ambas caras pelos similares a los del pecíolo, que son comunes en hojas jóvenes de numerosas especies de helechos. El mesófilo, como es común en hojas de lámina delgada, está formado por células cilíndricas ramificadas irregularmente formando parénquima esponjoso entre las epidermis superior e inferior, sin diferenciación de parénquima en empalizada.

La estela es una sifonostela ectofloica a diferencia de la de especies de Asplenium en las que es anfifloica, aunque esta diferencia puede deberse a que los ejemplares de S. nigripes examinados eran jóvenes (24 meses) o a característica propia de la especie. Las trazas foliares son simples, mientras que en

Asplenium son binarias o dobles (Chandra y Nayar, 1975). Las trazas radicales son solitarias, no ramificadas y similares a las de Asplenium.

AGRADECIMIENTOS. Se agradece al Dr. Carlos Sánchez Villaverde, del Jardín Botánico Nacional, Habana, Cuba, el habernos proporcionado hojas fértiles de Schaffneria nigripes Fée recientemente recolectadas, así como a los encargados de los herbarios ENCB y UAMIZ por permitirnos obtener esporas de los ejemplares Mickel 7333 y Riba 1313 respectivamente. Fotografías por J. Lodigiani.

\section{LITERATURA CITADA}

CHANDRA, S. y B.K. NAYAR. 1975. Vascular organization in the rhizome of spleenworts. J. Indian Bot. Soc. 54:188-199.

GóMEZ P., L.D. 1973. Contribuciones a la pteridología costarricense. IV. Los géneros Cheiloplecton, Schaffneria y Paltonium en Costa Rica. Rev. Biol. Trop. 21(1):91-101.

KLEKOWSKI, E.J., Jr. 1969. Reproductive biology of the Pteridophyta. III. A study of the Blechnaceae. J. Linn. Soc., Bot. 62:361-377.

NAYAR, B.K., F. RAZAy P. LATA. 1968. Gametophytes of some Indian spleenworts. Phytomorphology 18:467-478. 
NAYAR, B.K. y S. KAUR. 1971. Gametophytes of homosporous ferns. Bot. Rev. (Lancaster) 37(3):295396.

OGURA, Y. 1972. Comparative anatomy of vegetative organs of the pteridophytes. 2a. ed. Gebrüder Borntraeger, Berlin-Stuttgart. 502p.

PÉREZ-GARCÍA, B. 1988. Morfogénesis de gametofitos de Cyatheaceae (Pterophyta: Filicales). Tesis Doctoral Facultad de Ciencias. UNAM, México. 224p.

SASS, J.E. 1958. Botanical microtechnique. The Iowa State University Press, Ames, Iowa. pp. 69-70.

SMITH, A.R. 1981. Flora of Chiapas. (D. E. Breedlove, Edr.). Part 2. Pteridophytes. California Academy of Sciences.

THURSTON, E.L. 1969. Taxonomic significance of stomatal patterns in the ferns. Amer. Fern J. 59:68-79.

TRYON, R.M.y A.F. TRYON. 1982. Ferns and allied plants with special reference to tropical America. Springer Verlag, New York. pp. 652-654. 